NARRATIVAS (HIPER)MEDIÁTICAS BASADAS EN EL HUMOR: ANÁLISIS DE MEMES SOBRE LA COVID-19 Y MEDIDAS DE AISLAMIENTO SOCIAL EN ARGENTINA, MARZO A NOVIEMBRE DEL 2020

\author{
(HYPER) MEDIA NARRATIVES BASED ON HUMOR: \\ ANALYSING MEMES ABOUT THE COVID-19 AND SOCIAL \\ ISOLATION MEASURES IN ARGENTINA, FROM MARCH TO \\ NOVEMBER 2020
}

\title{
Flavia Demonte
}

flaviademonte@gmail.com

Doctora en Ciencias Sociales, Universidad de Buenos Aires (UBA). Investigadora Consejo Nacional de Investigaciones Científicas y Técnicas (CONICET). Docente Universidad Nacional de San Martín (UNSAM).

ORCID: https://orcid.org/0000-0003-3786-2635

\section{Andrea Mastrangelo}

andreaveronicamastrangelo@gmail.com

Doctora en Antropología Social. Universidad Nacional de Misiones (UNAM). Investigadora Consejo Nacional de Investigaciones Científicas y Técnicas (CONICET). Docente Universidad Nacional de San Martín (UNSAM).

ORCID: https://orcid.org/0000-0003-2844-6883

\section{(1) (1)(2)}

Esta obra está licenciada sob uma licença Creative Commons Attribution-NonCommercial-ShareAlike 4.0 International License.

\section{RESUMEN}

El objetivo del artículo es describir y analizar 292 memes que circularon por redes sociales de Internet sobre la covid-19 y la experiencia del Aislamiento Social Preventivo y Obligatorio en Argentina desde marzo a noviembre de 2020. Realizamos un análisis cualitativo, agrupándolos en categorías temáticas vinculadas con el proceso salud/enfermedad/ atención/prevención, identificamos los principales recursos utilizados y los relacionamos con el contexto en el que los memes fueron producidos y circulados. A través del análisis de los temas, los recursos utilizados y su relación contextual, reconstruimos narrativas vinculadas con la vida cotidiana durante la pandemia, la gestión de la política sanitaria, las prácticas preventivas de la población, el SARS-CoV-2 y la covid-19, el impacto del aislamiento social y la pandemia en la economía familiar, en la experiencia educativa, la salud mental y las miradas sobre el año 2020 y el futuro pospandemia. Concluimos que los memes, como productos socioculturales en estrecha relación con el contexto social, político, 
sanitario y cultural/mediático, construyeron una manera de narrar la incertidumbre y la reorganización de lo cotidiano durante la pandemia.

Palabras clave: covid-19; aislamiento social; medios de comunicación; narrativas.

\section{ABSTRACT}

The objective of the article is to describe and analyze 292 memes that have spread through Internet social networks about covid-19 and the experience of Preventive and Obligatory Social Isolation in Argentina, from March to November 2020. We have performed a qualitative analysis, grouping them into linked thematic categories such as health, disease, care, and prevention process. We have identified the main resources used and related them to the context in which the memes were produced and spread. Through the analysis of these issues, the resources used and their contextual relationship, we have reconstructed narratives related to daily life during the pandemic, the management of health policy, preventive practices of the population, SARSCoV-2 and covid-19, the impact of social isolation and of the pandemic on the family economy, education, mental health and perspectives on the year 2020 and the post-pandemic future. We have concluded that memes, as sociocultural products closely related to the social, political, health and cultural/media context, have built a way of narrating the uncertainty and reorganization of everyday life during the pandemic.

Keywords: covid-19; social isolation; media; narratives.

\section{INTRODUCCIÓN}

El 20 de marzo de 2020, a través del Decreto 297/2020 y ante la ausencia de tratamiento antiviral y vacunas que previnieran la Covid-19, el gobierno de Argentina decretó el Aislamiento Social Preventivo y Obligatorio (ASPO) para morigerar la circulación comunitaria del SARSCoV-2, fortalecer el sistema de salud y mitigar el impacto sanitario.

Como problema de salud y como acontecimiento sociopolítico, económico, ambiental y cultural, la Covid-19 y las medidas implementadas, son eventos que movilizan a la totalidad de la sociedad y a sus instituciones, impactando en la vida social, política y económica; en la vida cotidiana y en la subjetividad. El concepto de "hecho social total" planteado originariamente por Mauss $(1991)^{1}$ y recuperado por otros autores (MASTRANGELO, 2020) aporta fundamentos teóricos, epistemológicos y metodológicos para analizar la pandemia, las medidas implementadas y gran parte de sus impactos. Pero el concepto de proceso salud/enfermedad/atención/prevención (PSEAP) como un proceso básico de toda sociedad a nivel micro y macrosocial provee una lente complementaria. Según Menéndez, los procesos de SEAP causaron lo que ningún otro fenómeno podría generar: la experiencia existencial de 
padecer sincrónicamente en todo el planeta un problema similar, que no sólo amenaza nuestro trabajo, nuestras relaciones sociales o nuestras necesidades, sino también nuestras vidas (MENÉNDEZ, 2020). Y todo ello ocurre, "no como consecuencia natural de la pandemia, sino por las orientaciones, las evaluaciones y las acciones de las sociedades, grupos y sujetos" (MENÉNDEZ, 2020, p. 2). Estos conceptos nos permiten la comprensión amplia de las relaciones entre el virus, la enfermedad, las prácticas sociales, las instituciones contemporáneas y las simbolizaciones que de todo ello construimos los sujetos.

Como hecho social total y como parte de PSEAP, la pandemia y las medidas contextuales de contención de los contagios, nos permiten hacer múltiples preguntas para dar cuenta del hecho social pandemia en una perspectiva del Sur global. ${ }^{2}$ La pregunta que organiza este artículo es ¿cómo se narró (o simbolizó) públicamente la infección por SARSCoV-2 y la experiencia de "aislamiento social" en Argentina desde marzo a noviembre de 2020? El proceso de simbolización/narrativización de los acontecimientos en general -y del PSEAP en particular-, es el que da sentido a la realidad que vivimos (SAINT LAURENT; GLAVEANU; LITERAT, 2021), otorgándole significados que contribuyen a entender, tramitar y ubicarnos en esa realidad construida material y simbólicamente. Armus (2020) afirma que las epidemias del pasado nos dejaron relatos, diarios personales, que buscaban dar cuenta de una experiencia personal que también era colectiva. Así, y al igual que en el pasado, esta pandemia se transformó en una circunstancia privilegiada para observar fenómenos relacionados con la construcción simbólica del mundo vivido a través del estudio de diferentes discursos (AGUIAR; SOARES DE ARAÚJO, 2020).

Cotidianamente somos testigos de cómo los acontecimientos ya no los narran únicamente las instituciones mediáticas sino también los individuos y colectivos desde las redes sociales de Internet - whatsapp, facebook, twitter, instagram - (FRATICELLI; ANTIVERO, 2019). En este punto, diversos autores están de acuerdo en que estamos viviendo ya no en una sociedad mediática, ni siquiera mediatizada ${ }^{3}$, sino hipermediatizada (SCOLARI, 2020; CARLÓN, 2020; ESCUDERO CHAUVEL, 2020) e intensamente intertextual: la aparición de esta sociedad se inicia con Internet y la telefonía personal. Por tanto, si la sociedad globalizada facilitó la transmisión del virus a escala planetaria y que lo suframos sincrónicamente todos, la sociedad (hiper)mediatizada agilizó la producción y circulación discursiva (SCOLARI, 2020) del hecho social total. Los memes como piezas de comunicación se relacionan con lo personal, en tanto son narrativas que nos permiten procesar simbólicamente el hecho social Covid-19, a la vez que, como narrativas públicas, se ligan con "lo mediático" y con "lo virtual" (MASTRANGELO, 2020).

Teniendo en cuenta las herramientas teóricas citadas: el concepto de hecho social como parte inherente del PSEAP; el proceso de narrativiza- 
ción como expresión de la producción social de sentidos cristalizado en discursos diversos y el contexto de hipermediatización y confinamiento, hicimos foco en los memes, esa forma humorística de narrar la tragedia pandémica. Por tanto, el objetivo de este artículo es circunscribir el estudio de las narrativas públicas a la descripción y análisis de los memes sobre la Covid-19 y la experiencia del ASPO en Argentina (marzo a noviembre de 2020) que circularon por redes sociales de Internet, en sus dimensiones socio-antropológicas y comunicacionales: relatos humorísticos a través de los cuales podemos reconstruir maneras de narrar la incertidumbre y la reorganización de la vida cotidiana a la que estuvimos y aún estamos expuestos.

\section{LOS MEMES: DEFINICIONES Y ANTECEDENTES}

Como elementos de la sociedad hipermediatizada, los memes adquirieron protagonismo en las redes sociales desde inicios del milenio, transformándose en herramientas útiles para los científicos sociales (SAEZ; CARP, 2021). Diversos autores, de diferentes campos disciplinarios, propusieron numerosas definiciones: la primera fue considerarlos como unidades mínimas de transmisión o imitación cultural o gen cultural desde la socio-biología (DAWKINS, 1976 EN SOLA MORALES, 2020; SALGADO ANDRADE, 2020; COSTA DAMASCENO, 2020; BENASSINI-FÉLIX, 2020; CANCELAS OUVIÑAS, 2020; RIVAS CARMONA; CALERO VAQUERA, 2020 entre otros autores toman como referencia esta primera aproximación conceptual). Otras definiciones fueron complejizando su análisis e inscribiéndolo en el campo de la comunicación y la cultura, proponiendo a la vez modalidades de análisis: textos multimodales desde la comunicación y la lingüística (RIVAS CARMONA; CALERO VAQUERA, 2020); artificios semióticos puestos en circulación para ser intercambiados y replicados desde la socio-semiótica (ESCUDERO CHAUVEL, 2020); artefactos discursivos de expresión y discusión públicas (RUIZ MARTÍNEZ, 2018); artefactos culturales que cobran vida gracias a la "cultura de internet" desde perspectivas socio-antropológicas (BLACKMORE, 2000; JENKINS, 2009 apud COSTA DAMASCENO, 2020). En tanto documentos de comunicación y cultura, pueden llegar a ser indicadores de cómo es ideada una época (SAEZ; CARP, 2021), puesto que se relacionan con símbolos, estereotipos y códigos pertenecientes a un lugar y una época determinada (SOLA-MORALES, 2020).

Las definiciones propuestas tienen en común una particularidad: los memes son objetos-proceso en interrelación estrecha con otros memes, otros discursos y saberes. Son intensamente intertextuales y profundamente metadiscursivos (CARLÓN, 2002), por lo tanto, para ser cabalmente comprendidos deben ser analizados en relación con el contexto (social, político, económico, sanitario y cultural/mediático). Cualquier meme requiere de otros memes y material contextual para significar lo 
potencialmente fracturado, múltiple y la naturaleza incompleta de la narrativa misma (SAINT LAURENT; GLAVEANU; LITERAT, 2021). Al hacerlo, los memes son lúdicos y humorísticos, estilo retórico centralmente metadiscursivo pues genera la risa generando reflexiones, críticas o comentarios sobre un acontecimiento (REIS INSFRAN; SADDI CHAVES, 2020). Por tanto, pueden desafiar el papel de la autoridad de algunos discursos, como el político, el biomédico y el científico, por ejemplo, desenmascarando discursos jerárquicos. Es por ello que además de hacer reír, los memes permiten cuestionar el poder hegemónico ejerciendo resistencias y expresando discursos alternativos (SOLA-MORALES, 2020).

Si bien no son un objeto de investigación novedoso, puesto que es posible encontrar investigaciones sobre memes asociados con la política, la filosofía, la educación, el género; lo experimentado a nivel global por la pandemia fue un catalizador para la producción, circulación y análisis de memes e investigadores de diferentes países los analizaron desde múltiples perspectivas teóricas y metodológicas. Citamos algunas investigaciones con las que dialogamos en este artículo debido a similitudes de objetivos, delimitaciones temporales, enfoques y metodologías. Por ejemplo, en el contexto del confinamiento español Sola-Morales (2020) analizó los memes sobre la covid-19 publicados en Internet desde un análisis cualitativo temático recuperando herramientas de la socio-semiótica; Cancelas-Ouviña (2020) propuso un análisis etnográfico de los memes compartidos por redes sociales de Internet; Rivas Carmona y Calero Vaquero (2020) analizaron los memes difundidos a través de WhatsApp desde la perspectiva lingüística y en función de los efectos cognitivos pretendidos. En el contexto brasileño, Costa Damasceno (2020) y Reis Insfran y Saddi Chaves (2020) también analizaron memes. El primero realizó una etnografía digital para analizar los temas principales en las narrativas meméticas de un grupo de Facebook; los segundos realizaron un análisis dialógico del discurso sobre el uso de la cloroquina y la reacción de las personas mayores frente a la pandemia. Finalmente, Salgado Andrade (2020) analizó, utilizando las herramientas teóricas y metodológicas de la socio-semiótica y la etnografía digital, un corpus de memes sobre Covid-19 que circularon en México mostrando que, a través del humor, los discursos digitales refuerzan la discriminación y propagan ideologías globales. Quizá el trabajo de Escudero Chauvel (2020) sea el más amplio, comparado con los ya citados, puesto que analizó comparativamente el tratamiento de la información en la epidemia del SIDA a principios de los años noventa del siglo pasado con la pandemia de la Covid-19 en la primera mitad del siglo XXI. Complementario a ello, en su análisis de los memes circulados en Argentina, plantea una pregunta nodal para quienes nos interesa analizar el PSEAP desde los discursos hipermediáticos: 
nadie se reía ni osaba reírse del SIDA, pero todos nos reímos con el Covid-19. ¿Por qué? Porque la situación trágica que se haya parado la economía del planeta y la casi totalidad de la población esté confinada en sus casas o con circulación restringida se presta a la transformación humorística en la transgresión de la regla y de su puesta en discusión en sordina, mecanismo de base del humor (ESCUDERO CHAUVEL, 2020, p. 15).

\section{ABORDAJE METODOLÓGICO}

A través de nuestras redes personales seleccionamos, intencionalmente y por conveniencia, 292 memes gráficos (texto y/o imagen), con fines humorísticos relacionados con la infección por SARS-CoV 2, la Covid-19 y la experiencia del ASPO que circularon por las redes sociales de Internet (facebook, whatsapp y instagram) y desde 20 de marzo a 9 de noviembre de 2020. Entendemos que, si bien las redes sociales de Internet dan la ilusión de una comunicación transversal entre clases y géneros, producto de los algoritmos, pero también de los consumos culturales, la circulación de los memes se cierra en comunidades lingüísticas o grupos que le dan sentido al humor o la ironía. Desde esta perspectiva, entendemos que los memes incluidos intencionalmente en la muestra tienen sesgos de género, étnico-racial y de clase. De género en el sentido que no dan cuenta de las disidencias y particularidades del cuidado reivindicados por los feminismos populares. Étnico-racial, ya que no son referidas situaciones de discriminación o violencia que registramos en nuestro trabajo etnográfico en barrios populares (v. gr. población qom, violencia institucional contra jóvenes). Y de clase, ya que no se refieren a problemas de la vivienda, el hacinamiento ni la necesidad de salir a trabajar, sino que se enfocan en el encierro en la casa y los consumos que actualmente definen a la clase media (KESSLER; DI VIRGILIO, 2008). Excluimos de la muestra memes audiovisuales (como gift o videos), no humorísticos, con referencias a otras regiones, países o lugares. Y los analizamos con técnicas cualitativas, descriptivas y análisis de contenido. Optamos por analizarlos agrupándolos en categorías temáticas afines en las investigaciones sobre estos temas (COSTA DAMASCENO, 2020; SOLA-MORALES, 2020; CANCELAS-OUVIÑA, 2020) y emergentes del propio corpus. Una vez agrupados por temas, describimos cada uno de los memes, identificando los principales recursos (personajes y figuras retóricas) utilizados y los relacionamos con la información contextual. El propósito fue reconocer en cada meme narrativas principales, es decir, formas de contar la pandemia a través del humor, considerando que las temáticas dan significado a todo el mensaje (narrativa o storytelling).

\section{RESULTADOS}

Desde el 20 de marzo 2020, fecha en que se implementó el ASPO hasta fines de noviembre, momento en el que comenzó el Distancia- 
miento Social Preventivo y Obligatorio (DISPO) en el Área Metropolitana de Buenos Aires (AMBA) y el Área Metropolitana de Gran Resistencia (AMGR), los casos de covid-19 y las muertes por dicha causa aumentaron significativamente, prolongándose el confinamiento domiciliario como medida de mitigación (MS, 2020). En el contexto hipermediatizado en el que se está procesando la pandemia, los medios masivos y tradicionales no alteraron sus lógicas para informar (ESCUDERO CHAUVEL, 2020), resaltando narrativas basadas en el miedo, la alarma y el riesgo de contagiarse y morir. Sin embargo, una de las novedades más notables es que "lo risible" volvió a ser indisciplinado (FRATICELLI, 2020). Durante el proceso civilizatorio europeo, las instituciones expulsaron los géneros, temas y estilos ofensivos, y lo mismo hicieron, luego, los medios de comunicación, domesticando lo reidero e inaugurando fronteras y nuevas normas acerca de lo que podemos o no hacer chistes. Hoy en día, aquello que fue desterrado de la mediatización se propaga con la hipermediatización (FRATICELLI, 2020). Así y en oposición a las modalidades propias del discurso periodístico para informar sobre la pandemia, los memes produjeron otras narrativas sobre el mismo hecho.

Aprovechando el contexto de humor indisciplinado, pero de disciplinamiento social y biomédico (MASTRANGELO, 2020) analizamos los memes para reconstruir sus propias narrativas. El resultado de la clasificación y construcción temática de nuestro corpus, puede verse en la Tabla 1. Al igual que otras investigaciones (SOLA-MORALES, 2020; CANCELAS-OUVIÑA, 2020; ESCUDERO CHAUVEL, 2020), el aislamiento social y su impacto en la vida cotidiana; la política sanitaria; la prevención y cuidado; el virus y la enfermedad; el impacto del aislamiento en la economía familiar, la escolarización remota y la salud mental, tanto como las miradas sobre el año 2020 y el futuro pos-pandemia fueron las temáticas de los memes de nuestra muestra.

A continuación, presentamos los memes analizados dentro de las categorías temáticas, identificando los recursos más extendidos en ejemplos concretos y haciéndolos dialogar con el contexto en que estos mensajes se produjeron. 
Tabla 1 - Clasificación de los memes seleccionados, según las categorías temáticas

\begin{tabular}{|l|l|}
\hline \multicolumn{1}{|c|}{ Categorías temáticas } & N \\
\hline Covid-19 y Vida Cotidiana & 79 \\
\hline Covid-19 y Gestión de la Política Sanitaria & 60 \\
\hline Covid-19 y Prácticas Preventivas de la población & 42 \\
\hline SARS-CoV 2 y Covid-19 & 36 \\
\hline Covid-19 y 2020 y Futuro Pospandemia & 35 \\
\hline Covid-19 y otros (Economía, Educación, Vivienda) & 21 \\
\hline Covid-19 y Salud Mental & 19 \\
\hline Totales & $\mathbf{2 9 2}$ \\
\hline
\end{tabular}

Fuente: elaboración propia

\section{COVID-19 Y VIDA COTIDIANA}

Incluimos aquí los memes asociados con las prácticas realizadas en esta "nueva vida cotidiana" planteada por el aislamiento, desde los quehaceres domésticos; las prácticas alimentarias (las compras, las preparaciones, los momentos de consumo alimentario) y sus principales consecuencias (el aumento de peso corporal); la actividad física; las prácticas laborales y el teletrabajo; las prácticas recreativas y las prácticas sexo-afectivas.

La cotidianeidad planteada por el ASPO fue mostrada en los memes apelando al ridículo, la exageración, las emociones de agobio y desesperación ante el deseo de volver a la vida "normal" (SOLA-MORALES, 2020). Los memes interrogaron a la norma social (\#Quedate en casa) desplazándola hacia situaciones paradojales o imposibles, pero otorgando visibilidad a cuestiones culturales muy arraigadas en nuestra sociedad (ESCUDERO CHAUVEL, 2020). Así lejos de la sensación de "tener más tiempo", el ASPO trajo una sobrecarga de tareas con altos niveles de exigencia. El meme de la Figura $1^{4}$ muestra un gato (uno de los animales más extendidamente representados en nuestra muestra como personajes principales) que, apuntando con un arma de fuego intenta "terminar" o "aniquilar" las exigencias (o a las personas o instituciones que las enuncian), en tanto mandatos culturales y morales ${ }^{5}$, re-creados durante el ASPO: en tono imperativo, aparecen desde el mandato de la biomedicina nutricional de comer saludablemente y de realizar actividad física, pasando por abandonar la co-presencia en la educación ("clase online"), en las relaciones sociales en general ("hagamos videollamada"), pero en las sexo-afectivas en particular, obligándonos a probar otras formas ("probá sexting"). Todas estas múltiples exigencias bajo el mandato de preservar la salud mental ("no te deprimas") y, como si fuera poco, la exigencia de aprender algo nuevo. 
Figura 1 - Memes, vida cotidiana y mandatos del ASPO

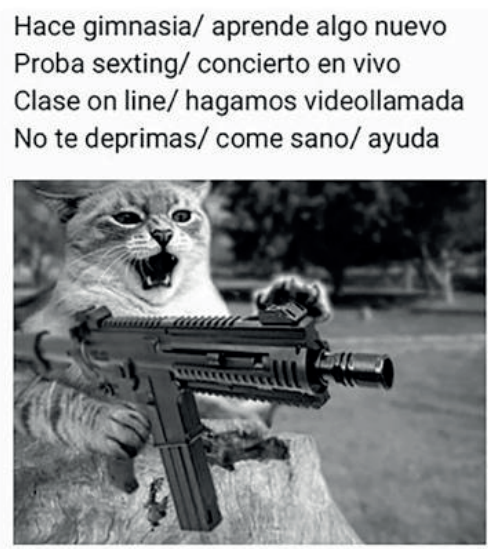

Fuente: Internet/redes sociales

Podemos ver el meme de la Figura 2 en relación a otros que representaron cómo se estaba transitando cotidianamente la pandemia, más allá de los imperativos propuestos por el meme de la Figura 1. Cocinar y limpiar fueron dos de las actividades a las que se les destinó más tiempo durante el inicio del ASPO (MARCÚS; BOY; BENITEZ et al., 2020). Pero no todos los integrantes del hogar le dedicaron la misma cantidad de tiempo. Si bien en nuestra muestra tenemos numerosos memes sobre quehaceres domésticos marcando esta práctica extendida, siempre la protagonista es una mujer, aunque ella no necesariamente esté presente visualmente. Este meme contrapone dos situaciones en la vida de una mujer (aparentemente sin hijos, de clase media, que le gusta viajar): una vida anterior a la pandemia y una vida durante el ASPO. No sabemos si vive en pareja, pero lo cierto es que la pandemia le cambió sus planes para el fin de semana largo de Semana Santa y, en lugar de verla sentada en un avión llegando a París, la vemos sentada frente a un lavarropas, con una imagen de éste como si recreara la ventanilla de un avión. En este caso no contempla la Torre Eiffel sino cómo gira el tambor del lavarropas mientras lava. Como vemos, y tenemos también numerosos ejemplos de este tipo en nuestra muestra, durante el ASPO se les pidió a las mujeres que asumieran, voluntaria y gratuitamente, una intensificación de las tareas de cuidado que ya hacían de modo predominante (MARCÚS; BOY; BENITEZ et al., 2020). Quedarse en casa significó para las mujeres "un infierno agobiante de disciplina de trabajo remunerado y no remunerado en el hogar” (LENGUITA, 2021, p.143) apenas visibilizado en los memes. En otras palabras, a través de sus imágenes y asociaciones, los memes de esta categoría temática mostraron que los patrones culturales reproducen desigualdades, aun en las circunstancias particulares del ASPO. 
Figura 2 - Memes, vida cotidiana y quehaceres domésticos

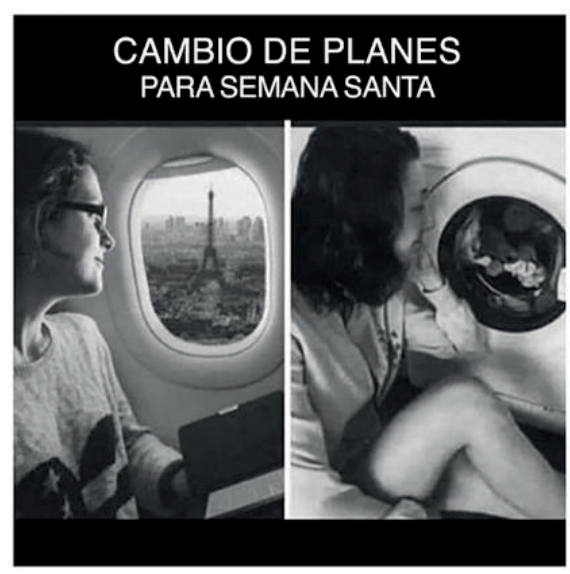

Fuente: Internet/redes sociales

Ubicándose por fuera de los mandatos de la Figura 1, la falta de rutina y el impacto emocional del ASPO hicieron que aumentara la frecuencia y volumen del consumo de alcohol (CAMAROTTI; JONES; GÜELMAN et al., 2020). El meme de la Figura 3 condensa la contradicción vivida entre lo que se debe hacer (los mandatos) y lo que se quiere/ puede hacer. Una mujer, sentada como si estuviera en una práctica de yoga, tomando una copa de vino. Tenemos que enfocar en la etiqueta de la botella de vino ("Yoga") y leer el texto que acompaña la imagen ("Solía ser una persona estresada hasta que comencé a probar el yoga") para comprender el sentido del meme que no es otro que: "Solía ser una persona estresada hasta que comencé a probar el vino”. La sustitución del vino por el yoga no sólo rompe con las recomendaciones de las prácticas saludables, tomadas como los mandatos culturales morales recreados durante el ASPO, sino que expresa una práctica "real", indicando no solamente la alta legitimidad social y tematización pública de esta práctica (ETCHEVERS; GARAY; PUTRINO et al., 2020; CAMAROTTI; JONES; GÜELMAN et al., 2020) sino, a diferencia del meme de la Figura 2, problematiza la mesura de la feminidad al admitir el derecho al consumo de alcohol (BALLESTEROS DONCEL, 2016).

Figura 3 - Memes, vida cotidiana y resignificación de los mandatos del ASPO

Solía ser una persona estresada

hasta que comencé a probar el yoga

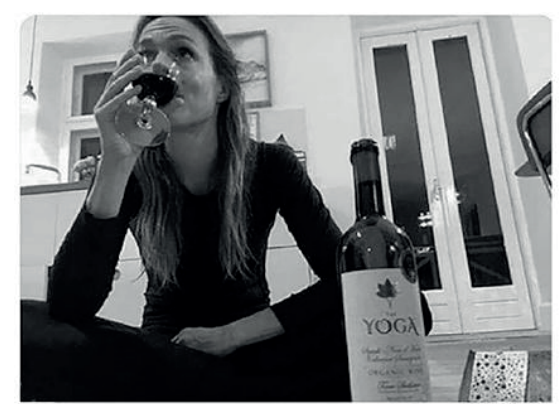

Fuente: Internet/redes sociales 
También incumpliendo los mandatos de comer sano (sinónimo de alimentación variada, moderada y equilibrada, DEMONTE, 2021) indicados por el meme de la Figura 1, el meme de la Figura 4 expresa los efectos en el peso corporal de las prácticas alimentarias durante el confinamiento. Una vez más tenemos como protagonista un animal (de la familia de los roedores) metido en un rollo de cartón. La imagen no diría mucho si no estuviera acompañada por el texto que indica "Mi panza”, como lo que sobresale del rollo; y "mis jeans", como lo que contiene, de manera muy apretada, el cuerpo, mostrando los efectos de comer de más. Numerosos son los memes que narran estas situaciones durante el ASPO y, como vimos y veremos, no se dan en el vacío, sino que relatan algunos de los aspectos vinculados con la alimentación (de aquellos que pudieron acceder económicamente a los alimentos) durante el aislamiento. Al tener mayor tiempo disponible, las personas que pudieron, salieron a comprar alimentos y cocinaron más; hubo además un aumento de la comida preparada en casa (comida casera), un comer enfocado en el placer y extendidamente desestructurado (salteando momentos reglados como desayuno, almuerzo, merienda y cena y dominando el snacking o picoteo), asociado con la ansiedad y el estrés. Harinas, azúcares y alcohol (como vimos con el meme de la Figura 3) fueron los rubros que más aumentaron su consumo durante el ASPO, mientras que frutas y verduras fueron los que más disminuyeron (SUDRIÁ; ANDREATTA; DEFAGÓ, 2020). El exceso de peso pronto fue percibido por los especialistas como indicador preocupante según los estándares de normo-peso en simultáneo con la profusión del discurso gordo-odiante (INADI, 2020).

Figura 4 - Memes, vida cotidiana e incumplimiento de los mandatos del ASPO

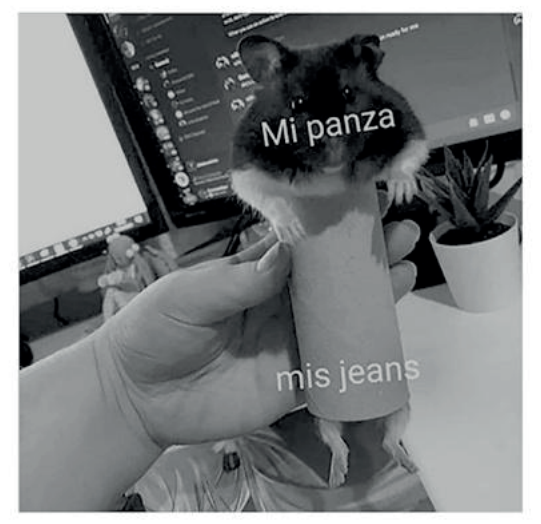

Las prácticas sexo-afectivas también se incluyeron en los mandatos revisitados del ASPO, como vimos en la Figura 1, aunque algunas investigaciones refieran que la vida sexo-afectiva empeoró durante la misma 
(ETCHEVERS; GARAY; PUTRINO et al., 2020). En abril de 2020, el ministerio de Salud de la Nación brindó recomendaciones sobre sexo seguro en tiempos de Covid-19, promoviendo videollamadas y sexo virtual o sexting. Dicha recomendación fue retomada por los medios de comunicación y dio lugar a múltiples memes, inscribiéndolas en los mandatos recreados por el ASPO (Figura 1) en esta "nueva" normalidad: tener sexo sin co-presencia física para prevenir la transmisión del virus. Ese es el contexto en el que aparece el meme de la Figura 5. Se trata de la imagen de una mujer joven -adolescente-, y un texto que dice: "Cuando te recomiendan sexo virtual para evitar el contacto físico, pero vos no tenés sexo ni casual, ni virtual, ni de lástima”. ¿Quién recomienda? La máxima autoridad sanitaria a nivel nacional. ¿Quién es el personaje que muestra la imagen? La mujer de la imagen es un personaje de la serie británica Sex Education ${ }^{6}$ : Lily Iglehart, una chica que escribe novelas eróticas extraterrestres, y está decidida a tener relaciones sexuales lo antes posible pero no lo consigue tan fácilmente. El meme no tendría el sentido que pretende sin la articulación entre imagen y texto, asumiendo un conocimiento por parte del lector sobre la serie y las características del personaje, confirmando la relación entre memes como fenómeno hipermediatizado e intertextual. Al igual que el meme de la Figura 3, aquí también se problematiza la feminidad al admitir abiertamente el deseo sexual (BALLESTEROS DONCEL, 2016).

Figura 5 - Memes, vida cotidiana e impotencia frente a los mandatos del ASPO

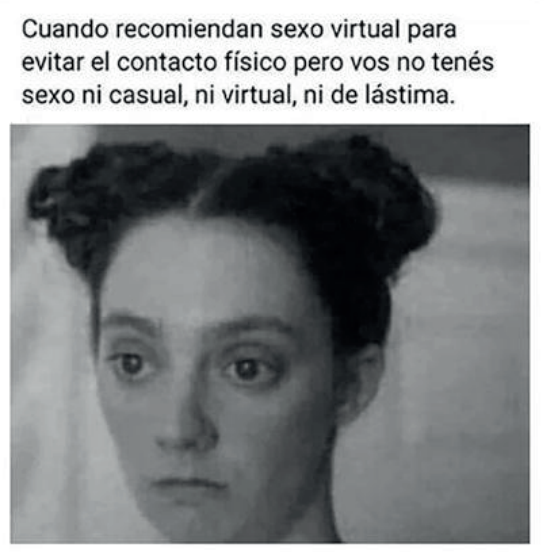

Fuente: Internet/redes sociales

Quizá lo que une a todos los memes de esta categoría temática sea una invitación a reírnos, marcando las alteraciones prácticas en el cotidiano, en las relaciones sociales y sexo-afectivas y de nuestros ritmos biológicos. Sin embargo, y aun cuando en los inicios hubo un alto acatamiento del ASPO, el retorno a la "vida normal" se presentaba como un anhelo para la mayoría de la población, porque con el paso del tiempo nuevas exigencias se montaron a las ya existentes. 


\section{COVID-19 Y GESTIÓN DE LA POLÍTICA SANITARIA}

Analizamos aquí los memes asociados con la política sanitaria. El rol del Estado se mostró central: numerosos memes muestran la disputa entre Estado y mercado, el Estado como garante del derecho a la salud o el Estado como cercenador de las libertades individuales. En Argentina, las políticas públicas nodales fueron el diagnóstico precoz y masivo, el aislamiento de casos positivos y sus contactos estrechos, el "distanciamiento social" (nombre dado a la distancia de seguridad entre personas en el espacio público), la promoción del lavado de manos, el uso de barbijos y las intervenciones con tecnologías médicas intensivas (respiradores, sueros hiperinmunes). Pero todas estas medidas se desplegaron en un escenario de incertidumbres biomédicas (por el desconocimiento del virus y las formas de prevenirlo y tratarlo) y de la salud pública (por la falta de certeza respecto de cuándo masificar el uso de barbijos; por cuánto tiempo y cuán estricto debería ser el "aislamiento social”; cómo manejar la tensión entre el cuidado de la salud y la paralización de la economía, entre otros planteados por Armus, 2020). De estas incertidumbres, una de las más recurrentes en los memes analizados fue la duración del ASPO. En el meme de la Figura 6 vemos una placa de fondo negro con letras blancas cuyo texto expresa la idea del ASPO como experiencia interminable. La referencia temporal a las dos semanas se relaciona con hecho de que el gobierno nacional, en los primeros meses, siempre prorrogaba el ASPO por dos semanas.

Figura 6 - Memes y gestión de la política sanitaria (duración del ASPO)

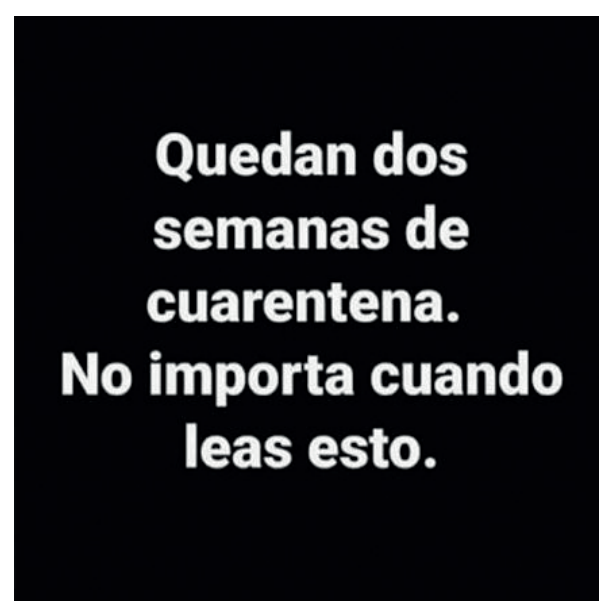

Fuente: Internet/redes sociales

En los memes agrupados en la Figura 7, mediante operaciones metafóricas ${ }^{7}$ se adjetivó la duración del ASPO, caracterizándolo como "eterno" personificándolo a través de protagonistas (como Mirtha Legrand y Eva Perón) de la cultura popular y política y/o "duradero" expresándolo a través de objetos (como el automóvil Renault 12) asociados a esas características. 
Figura 7 - Memes y gestión de la política sanitaria (duración del ASPO)



\section{- Esperemos que la \\ cuarentena no dure mucho.}

La cuarentena:

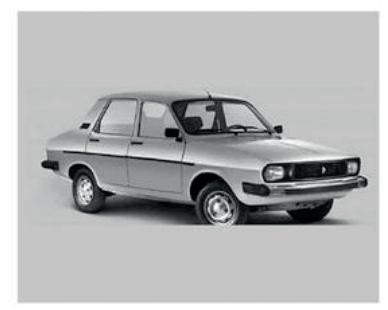

Fuente: Internet/redes sociales

A diferencia de los memes mostrados en las Figuras 6 y 7, el grupo de la Figura 8 abandona la circularidad del primero y la idea de la eternidad del segundo, y expresa un horizonte temporal definido: las fiestas navideñas que se disfrutan en diciembre. No expresan un alivio, todo lo contrario, marcan que aún queda bastante tiempo de confinamiento y lo hacen con diferentes recursos. En la primera, se muestra la figura del presidente, en sus frecuentes conferencias de prensa que, en lugar de recomendar las típicas medidas preventivas, recomienda aprender la receta del pan dulce -típico consumo navideño- como expresión de duración del ASPO, recogiendo además aspectos propios de lo analizado en los memes asociados con la vida cotidiana ("aprendé algo nuevo", de la Figura 1, pero también cocinar como práctica extendida). La segunda, muestra a los protagonistas principales de las fiestas navideñas católicas (Jesús, María y José, además de los Reyes Magos) hablándonos respecto "de lo que se siente que te guarden en febrero y te saquen en diciembre", realizando una comparación entre el ASPO y el armado del "pesebre". Según las tradiciones el pesebre de Navidad representa el nacimiento de Jesucristo y según la costumbre, suele armarse el 8 de diciembre - el Día de la Virgen - junto con el árbol de navidad y se lo desarma luego del 6 de enero, pasado el Día de los Reyes Magos. Entre febrero y noviembre suelen guardarse todos estos objetos hasta la próxima navidad. Así, pan dulce y pesebre marcaron una expectativa de finalización del ASPO frente a la indefinición temporal de los primeros mensajes. 
Figura 8 - Memes y gestión de la política sanitaria (duración del ASPO)
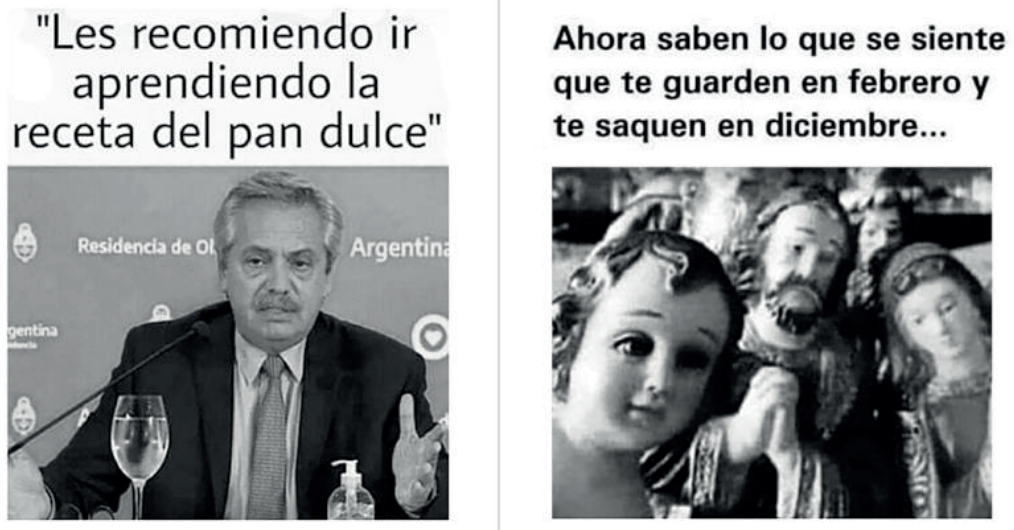

Fuente: Internet/redes sociales

Lo que une a los memes ejemplificados de esta categoría son las incertidumbres propias de la gestión política de la salud pública. Este interrogante rápidamente se desplazó hacia los sujetos, simbolizando las incertidumbres con la apelación a diferentes recursos retóricos.

\section{SARS-CoV- 2 Y COVID-19}

Además de narrar a través del humor la nueva vida cotidiana y las incertidumbres de la política sanitaria, también hubo memes sobre el propio virus y la enfermedad: memes que relatan aspectos vinculados con su origen, los síntomas, su distribución en las diferentes áreas del país, la duración de la pandemia y la aparición de la vacuna como solución. Como ejemplo, agrupamos memes vinculados con esta categoría en la Figura 9. La primera imagen muestra a un hombre llorando mientras que el texto plantea una de las hipótesis de orden conspirativo que, hasta el presente, sobrevuelan sobre el origen del SARS-CoV-2: que, en vez de pasar de un animal a un humano, fue creado en un laboratorio chino, específicamente en el Instituto de Virología de Wuhan. La segunda imagen muestra a un ex presidente de Argentina (Carlos Menem) citado en una de sus frases instalada en la memoria argentina ${ }^{8}$. Este meme cita esa frase en relación con el debate desatado en Ciudad de Buenos Aires sobre los "runners" y la incidencia de su práctica - típica de la clase media-alta de un barrio de altos ingresos como Palermo- en la velocidad de propagación del virus y el ingreso de éste en barrios de ingresos económicos bajos del conurbano bonaerense, como La Matanza, Aldo Bonzi y otras zonas con "barrios populares". Se trata de un ejemplo de meme de humor exclusivamente local, que implica contar con una serie de conocimientos previos para ser comprendido: la frase desopilante de Menem, el debate planteado por la demanda de los runners, la asociación entre velocidad del running y velocidad de transmisión viral, la asociación de esta práctica con el barrio de Palermo y el conocimiento de algunos barrios populares incluidos en el Gran Buenos Aires. Final- 
mente, la tercera imagen muestra a Spider-man en sus diferentes versiones $^{10}$, cada una representando a coronavirus, alergias y gripe común, mostrando las dificultades para diferenciar una de la otra por su sintomatología común.

Figura 9 - Memes y SARS-CoV-2 y Covid-19
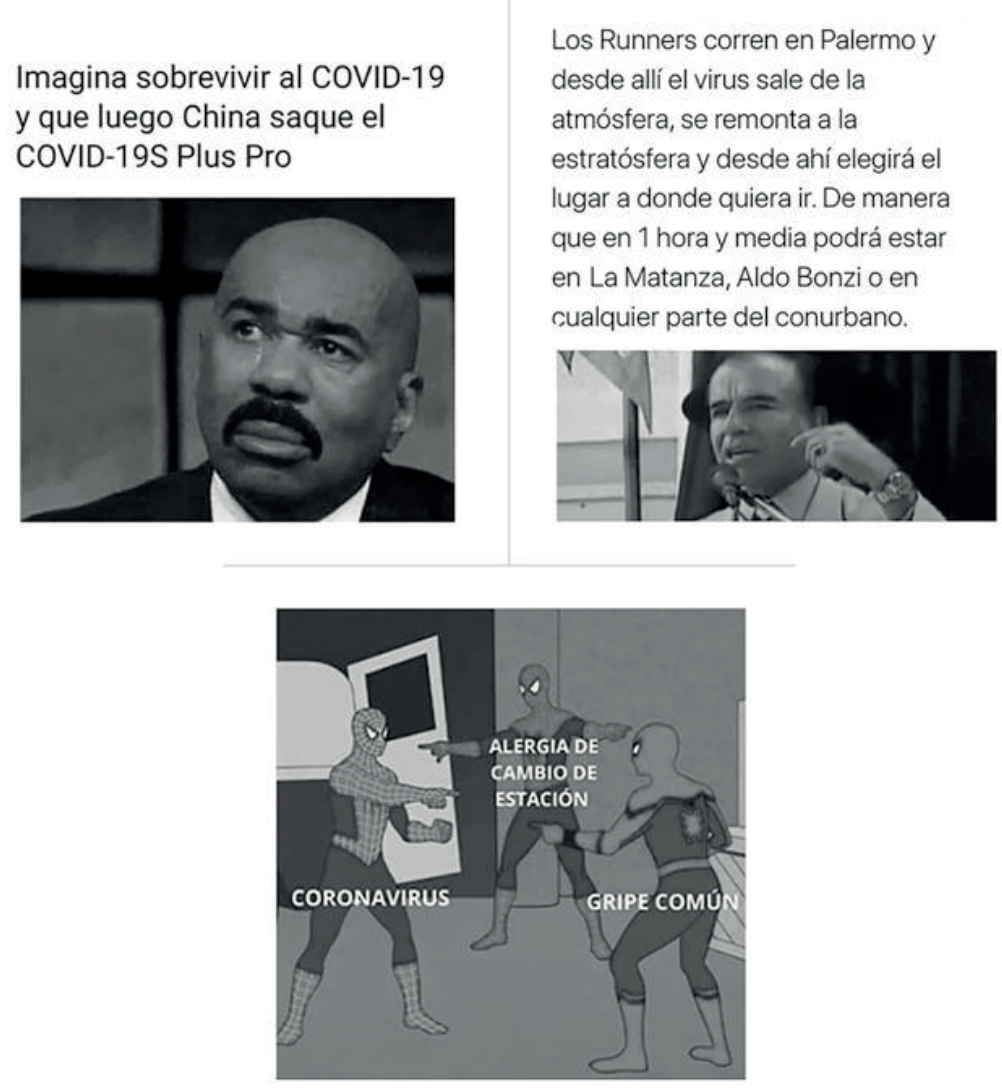

Fuente: Internet/redes sociales

\section{COVID-19 Y PRÁCTICAS PREVENTIVAS DE LA POBLACIÓN}

Incluimos aquí los memes asociados con las prácticas preventivas personales como la higiene de manos y el uso de barbijos, tapabocas o mascarillas y el distanciamiento social. Para ejemplificar, en la Figura 10, agrupamos algunos de los memes que, siempre desde el humor, representan estas prácticas transformadas en cotidianas. Analizar los memes en relación con esta categoría temática es un indicador más de la hegemonía de la biomedicina como práctica y saber legitimados para enfrentar la pandemia. A las ya mencionadas, las autoridades sanitarias recomendaron no automedicarse con fármacos ni otros medicamentos, ignorar los mensajes por Internet $\mathrm{u}$ otros medios que indujeran a determinados usos y comportamientos. Por si fuera poco, el sector sanitario indicó cuáles eran los principales síntomas de la enfermedad para que nosotros mismos hiciéramos un diagnóstico inicial y decidiéramos si ir o no al médico (MENÉNDEZ, 2020). En estas recomendaciones, gran 
parte de las prácticas preventivas están concentradas en el quehacer de la población (MENÉNDEZ, 2020). En la primera de las imágenes del grupo de la Figura 10 vemos un envase de una vacuna, que lleva una etiqueta en su nombre "Nitrato de salir" sostenida por una mano con guante quirúrgico y debajo de ésta lo define como "Tratamiento Covid 19". A la ausencia de vacuna, sustituye su eficacia para su prevención o tratamiento la norma "Quédate en casa". La segunda y la tercera de las imágenes muestran otra de las prácticas preventivas: el uso del barbijo y la higiene con jabón, alcohol en gel o hipoclorito de sodio (comúnmente conocida en Argentina como Lavandina). En el caso de la segunda muestra lo extendido del uso de este producto al inicio de la pandemia para limpiar superficies ya que el meme muestra que todas las personas olían a lavandina, transformándola en un perfume: Eau de Lavandín, y con el término eau (agua en francés) refiere además a una de sus características más notorias: la intensidad, profundidad y duración de su olor. En el caso de la tercera, representa el barbijo y el alcohol en gel como objetos que denotan marcas de época y memoria colectiva. Pero más allá de su funcionalidad (para la producción del cuidado), en este meme son presentados como objetos-signos/símbolo, evocadores de un tiempo/espacio, como expresiones metonímicas ${ }^{11}$ de ese espacio/tiempo. $\mathrm{Al}$ presentar estos objetos con este recurso propone también un ejercicio de proyección liberador a la vez que perturbador: en 2035 los niños de hoy serán adultos y deberán apelar a la memoria para recordar el uso de estos objetos para el cuidado (es decir, la pandemia será un evento del pasado), pero lo que devolverá esa memoria justamente es una infancia signada por una pandemia.

Figura 10 - Memes y prácticas preventivas de la población
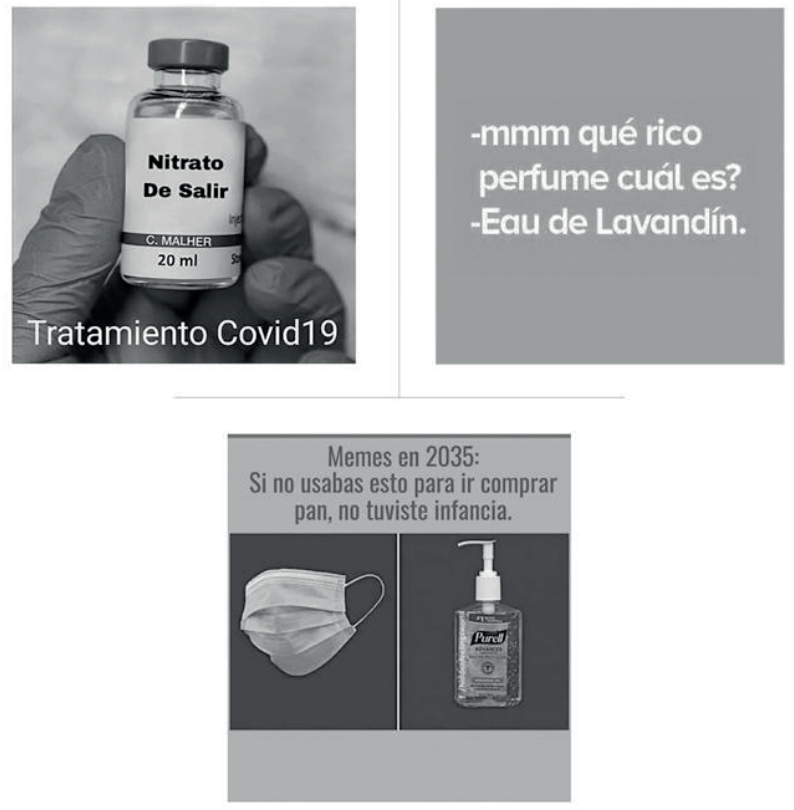

Fuente: Internet/redes sociales 


\section{COVID-19, ECONOMÍA Y EDUCACIÓN}

Incluimos aquí los memes relacionados con el impacto en la microeconomía de las familias de la paralización de la economía a causa del confinamiento. A pesar de las medidas tomadas por el gobierno para morigerarlo a través de medidas de apoyo económico a las jubilaciones mínimas, la Asignación Universal por Hijo, la Tarjeta AlimentAR y la creación de nuevos programas de transferencia de ingresos como el Ingreso Familiar de Emergencia -IFE- y Programa de Asistencia al Trabajo y la Producción -ATP- (ASSUSA; KESSLER, 2020; KESSLER; BENZA, 2020), la pérdida de ingresos en los hogares fue profunda (INDEC, 2020) y como consecuencia aumentaron los niveles de pobreza (DÍAZ LANGOU; KESSLER; DELLA PAOLERA et al., 2020). Uno de los memes agrupados en la Figura 11, muestra una situación de penuria cotidiana dada por la escasez de dinero aun en personas bancarizadas y con hasta dos cuentas bancarias. A través de una típica "Consulta de Saldo", en lugar de mostrar el dinero disponible dice "re contra re mil seco", apelando a un modismo donde "seco" significa que se cuenta con poco dinero o no se lo posee. Frente a esta realidad de escasez de dinero, una segunda "Consulta de Saldo", en lugar de mostrar el dinero disponible dice "al pedo tenés dos cajas", también apelando a una expresión muy extendida que significa que, en este caso, tener dos cajas de ahorro no sirve para nada si no se dispone de dinero.

También incluimos los memes relacionados con el impacto del confinamiento en la educación, pero fundamentalmente en las nuevas formas asumidas por ella y en la experiencia de vivirlas, aun reconociendo que el impacto de la pandemia en este campo es más amplio y complejo y que, por tanto, requiere otro tipo de análisis (KESSLER; BENZA; 2020; DÍAZ LANGOU; KESSLER; DELLA PAOLERA et al., 2020). La norma (“Quedate en casa") implicó la readecuación de un sistema educativo centrado en la co-presencia de docentes y alumnos a una forma de educación remota (por correo electrónico o mensajes de whatsapp, pues no está garantizada la conectividad a internet para conexión sincrónica en ningún nivel educativo público). Por lo tanto, en pocos días hubo que generar estrategias en un contexto de profunda desigualdad tanto tecnológica como de competencias para la apropiación de la tecnología en los procesos de enseñanza-aprendizaje. A través de la reutilización de una imagen que fue viralizada en 2018, el meme que refiere a la educación en la Figura 11 muestra el cimbronazo en la vida cotidiana de familias y estudiantes de este cambio abrupto en las condiciones educativas. En su origen, este meme mostraba la imagen de este niño guatemalteco quien había pedido a su tío que lo disfrazara de zombie para las Fiestas de Halloween. Esa imagen fue viralizada con el texto "Quería disfrazar a mi sobrino de zombie, pero me quedó como abogado de la Defensa Pública Penal”. Luego, con la viralización el texto fue cambiando y adecuándose la imagen en función del contexto. Así 
fue que durante la vigencia del ASPO y la educación remota (con la utilización de una de las plataformas más difundidas como el Zoom), el meme fue reeditado, metaforizando sus efectos: un niño-zoombie, y encarnando las características de éste luego de una cursada no presencial y vía Zoom. De acuerdo con sus orígenes, un zombie es una persona que se supone muerta y que ha sido resucitada, incapaz de pensar y actuar por sí mismo puesto que han dominado su voluntad a través de la hechicería. En parte, por este origen se asocia con zombie a una persona como atontada, que se comporta como un autómata. Para cerrar el sentido del meme, frente a la pregunta “ ¿y?, ¿cómo va ese final de cursada por zoom?". El niño podría responder: me siento un zombie: muerto en vida, como un autómata y atontado.

Figura 11 - Memes e impacto en la economía y en la educación


Fuente: Internet/redes sociales

\section{COVID-19, SALUD MENTAL Y MALESTARES}

Incluimos aquí los memes asociados con el impacto subjetivo y emocional del aislamiento, tanto en la población como en los equipos de salud relevados por otras investigaciones (JOHNSON; SALETTI-CUESTA; TUMAS, 2020; ETCHEVERS; GARAY; PUTRINO et al., 2020; ARDILA-GÓMEZ; ROSALES; FERNÁNDEZ et al., 2021; RODRÍGUEZ CEBERIO; JONE; BENEDICTO, 2021), que expresan la incertidumbre propia de la coyuntura epidémica (por el futuro, por las consecuencias sociales y económicas), la responsabilidad (por el cuidado de uno mismo y de los demás), la angustia (tedio, aburrimiento, tristeza y depresión), los "nervios" y se sintetizan en dos malestares: el miedo y la ansiedad como efectos del aislamiento y la propia experiencia de la pandemia (RODRÍGUEZ CEBERIO; JONE; BENEDICTO, 2021).

El impacto en la salud mental fue profundo en la primera parte del ASPO, asociado a la ruptura en la cotidianidad anterior a la pandemia (como vimos en las Figuras 2, 3, 4 y 5), la pérdida de previsibilidad temporal (como vimos en las Figuras 6, 7 y 8 ) y las propias incertidumbres planteadas por la ciencia y las instituciones biomédicas respecto del vi- 
rus y la enfermedad. A ello se sumaron otros factores más concretos como la escolaridad y los problemas de acceso a la tecnología para padres y estudiantes, la escasez de equipos tecnológicos para el estudio y el trabajo domiciliario, la falta de espacio y privacidad, la extrema soledad en quienes carecen de convivientes, además de los problemas económicos -representados también en los memes de la Figura 11- (RODRÍGUEZ CEBERIO; JONE; BENEDICTO, 2021). En nuestra muestra identificamos memes en relación con estos malestares, pero por razones de extensión elegimos uno (Figura 12). Ese meme recoge, a través de una parodia, el protagonismo adquirido por la ciencia y los científicos en este momento y presenta lo que sería un nuevo avance tecnológico: transformar la ansiedad en electricidad. La ansiedad, como una emoción orientada hacia la idea de futuro (RODRÍGUEZ CEBERIO; JONE; BENEDICTO, 2021) y provocada por las incertidumbres biomédicas y de salud pública -fundamentalmente el ASPO- es el malestar más recurrentemente reconocido como impacto del confinamiento en la salud mental (Ibídem). Por tanto, el meme sintetiza en una narrativa cómo impactan en nuestra salud mental la pandemia y el ASPO (aumento de ansiedad) en el marco de otras narrativas vinculadas con el protagonismo de la ciencia (en su versión de investigación biomédica, clínica y experimental) como patrón de todo saber e institución salvadora, tanto en lo que respecta al comportamiento del virus y su genómica, como a la eficacia de las vacunas y las terapéuticas.

Figura 12 - Memes e impactos en la salud mental



Fuente: Internet/redes sociales

\section{COVID-19, 2020 Y FUTURO POSPANDEMIA}

Incluimos en esta categoría los memes referidos a las miradas sobre el 2020 y las hipótesis sobre un futuro pospandémico. Expresan narrativas que se actualizaron en discursos orales y escritos aventurados por diferentes actores sociales que oscilaron entre el optimismo de quienes vaticinaron que todo cambiará y que serán cuestionadas las bases de 
la desigualdad, y el pesimismo de quienes avizoran que nada cambiará (KESSLER; BENZA, 2020). Como ejemplo del primer caso, elegimos el meme de la Figura 13 que trae a escena, a través del recurso de la ironía, la narrativa sobre el fin del capitalismo o, menos ambicioso, la crisis del modelo de desarroll neoliberal criticada por Menéndez (2020) y propuesta por autores como ŽıžEK (2020) con su concepto de comunismo o Zibechi (2020) con su idea de destrucción de la globalización neoliberal, ofreciendo otra mirada: no solamente la incapacidad de "adoctrinar" al capitalismo, sino inclusive su capacidad adaptativa, aun con sus recurrentes crisis. Más allá de la ironía, se trata de una respuesta a la idea de que la situación planteada por la Covid-19 es un parteaguas, un evento decisivo que marca un futuro distinto al actual -eso de "ya nada será igual”- (ARMUS, 2020).

Figura 13 - Memes, sistema capitalista y pandemia

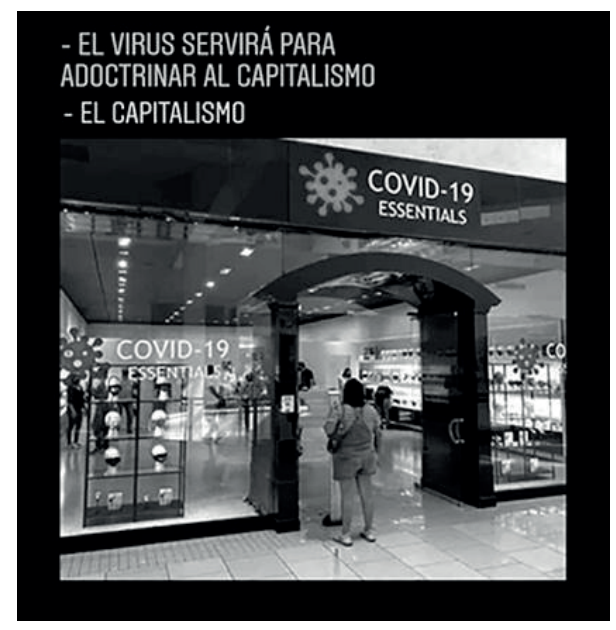

Fuente: Internet/redes sociales

La promesa de un futuro pos-pandémico más reflexivo y benigno (JOHNSON; SALETTI-CUESTA; TUMAS, 2020) también forma parte de esta hipótesis sobre la pos-pandemia. Como afirma una de las investigaciones sobre la salud mental, la pandemia catalizó aspectos valorados como positivos para la sociedad, como un sentido de responsabilidad y cuidado, así como la interdependencia de las personas y la posibilidad de reflexión sobre sí mismos y sobre la sociedad en su conjunto (JOHNSON; SALETTI-CUESTA; TUMAS, 2020). Los memes agrupados en la Figura 14 representan, apelando también al recurso de la ironía, algunas de las contradicciones planteadas en estas narrativas sobre la pandemia. Una de ellas, ejemplificada en la primera imagen, recoge una de las narrativas que avizoraba la caída de la creencia en la supremacía de los seres humanos sobre la naturaleza (ESCUDERO CHAUVEL, 2020; JOHNSON; SALETTI-CUESTA; TUMAS, 2020) bajo la consigna como la revolución será ecológica o no será (MENÉNDEZ, 2020), muestra un ser humano con armadura que levanta en su mano a un pequeño 
animal, ambos representando a una supuesta "nueva humanidad" que replantea una "nueva" relación con los animales. La imagen muestra por el contrario una relación defensiva y de control. Frente a la ironía del primero respecto del optimismo acerca del replanteo de la relación naturaleza-cultura; la segunda utiliza como recurso la película Mad Max ${ }^{12}$ y a su protagonista en un escenario distópico, como parodia de lo que será el 2021, ironizando sobre ese futuro pos-pandémico más benigno. Como el meme de la Figura 5, éste no tendría el sentido que pretende sin la articulación entre imagen y texto, asumiendo un conocimiento por parte del lector sobre el argumento de la película, confirmando la relación entre memes como expresión de los fenómenos asociados con la mediatización (el mundo del cine), la hipermediatización, la intertextualidad y las estrategias singulares para relatar aspectos de la pandemia.

Figura 14 - Memes, sistema capitalista y pandemia
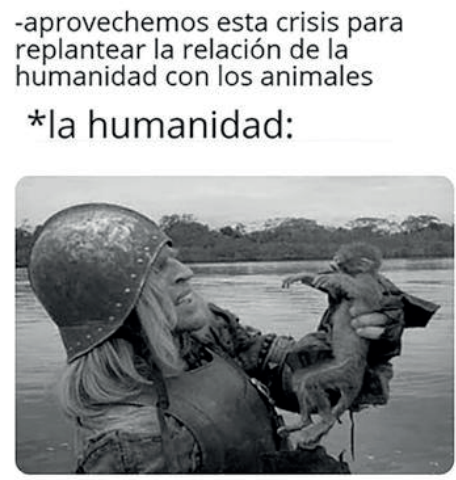

No quiero ser pesimista pero Mad Max está ambientada en 2021.

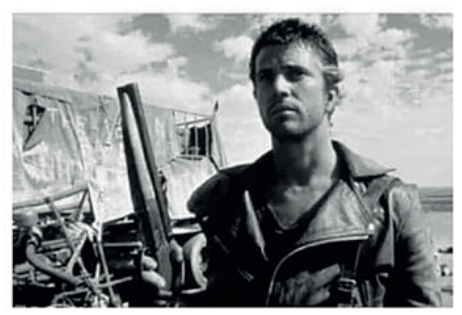

Fuente: Internet/redes sociales

En cualquiera de los casos (entre las miradas más optimistas y las miradas más pesimistas), los memes no hicieron más que reírse de ellas, mostrando también ese doble juego pretendido propio de su formato y su gramática: mientras nos reímos, pensamos, tanto individual como colectivamente.

\section{DISCUSIONES Y CONCLUSIONES}

En un cruce entre la comunicación y la antropología abordamos el análisis de las narrativas públicas vinculadas con la infección por SARSCoV-2 y la experiencia del ASPO, entendido como el contexto más inmediato que delimita los procesos de producción de sentidos (AGUIAR; SOARES DE ARAÚJO, 2020). Dentro de las narrativas públicas, circunscribimos nuestro análisis a los memes porque, aunque tienen estrecha relación con las narrativas mediáticas (hipermediatización), ponen en juego discursos de otros actores sociales (intertextualidad y metadiscursividad) y su creación se da en forma participativa (se pueden re-crear y compartir en cualquier teléfono móvil). En este sentido, las narrativas 
propuestas por los memes, si bien son públicas - porque los memes buscan desenfrenadamente la replicación y compartirse con otros- expresan relatos asociados con la experiencia individual y también colectiva que, a diferencia de los de periodistas, académicos y políticos, no están editorializados por el deber ser. Nos mostraron a través del humor las miradas, los saberes, las prácticas y también las incertidumbres planteadas por la pandemia, contribuyendo (y mucho) a procesar, por medio de simbolizaciones, la emergencia sanitaria y la intervención del Estado en la gestión de políticas - el ASPO y las medidas de apoyo económico como el ATP y el IFE-. Desde una perspectiva diferente a la de otros actores sociales, sin dejar de dar cuenta de los malestares generados por la reestructuración de la vida doméstica y el cotidiano asociado con las medidas de contención, los memes nos contaron a través de historias mínimas, parciales (SAINT LAURENT; GLAVEANU; LITERAT, 2020) y alejadas de las típicas narrativas que apelan a las metáforas de la catástrofe natural, de la guerra o del enemigo y las víctimas para entender y enfrentar la pandemia, pequeños mundos posibles. Por ser fácilmente circulables, se constituyen en fragmentos compartidos de circunstancias de la vida cotidiana (ESCUDERO CHAUVEL, 2020) y prácticas de cuidado que expresan miradas y saberes no hegemónicos sobre la información disponible.

Así, mediante los memes pudimos reconstruir, al igual que las investigaciones tomadas como antecedente, narrativas inherentes al PSEAP vinculadas con las transformaciones en nuestra vida cotidiana y los diversos escenarios en los que ésta transcurre -tanto los mandatos a ella asociados como las negociaciones y resistencias de esos mandatos-, con la gestión de la política sanitaria y las incertidumbres, con las propias prácticas preventivas y cuidados de la población para prevenir la infección por SARS-CoV-2, y las explicaciones respecto de su etiología, sus formas de transmisión y mecanismos de prevención. Asimismo, a través de los memes recogimos relatos sobre el profundo impacto de la pandemia y la experiencia del ASPO en relación con los roles patriarcales de género (sobre exigencia a las mujeres de prácticas de cuidado y trabajo no remunerado), la economía familiar (la merma o ausencia de ingresos familiares), en la experiencia educativa (remota y desigual) y en la salud mental (los sentimientos y malestares psicológicos, como ansiedad y angustia).

Aunque se utilicen diferentes escenarios y recursos para representarlos (textos, personajes de ficción o animales) el protagonista principal de las narrativas es el propio espectador, el colectivo confinado que sufre la situación de excepcionalidad, como lo mostraron también otras investigaciones (SOLA-MORALES, 2020; CANCELAS-OUVIÑA, 2020). $\mathrm{El}$ "nosotros" en aislamiento, que no sabe qué hacer para hacer pasar el tiempo (cocinar y comer más; limpiar y ordenar; practicar yoga; teletrabajar o tener clases por Zoom; experimentar con el sexting), que busca 
vías de escape para reírse de sus penurias económicas cotidianas en un contexto de miedo, ansiedad e incertidumbre sobre el (eterno) presente pandémico.

Finalmente, los memes no sólo nos propusieron otros relatos del día a día de la emergencia sanitaria y sus impactos, también nos permitieron recuperar, desde la ironía -como recurso inherente a su género y formato- reflexiones sobre el impacto de la pandemia en nuestra manera de vivir, producir y consumir a partir de memes sobre el 2020 y el futuro pospandemia, mostrando de este modo, sus pretensiones: mientras nos reímos, pensamos.

Así, analizados los memes como productos socioculturales marcadores de una época y, por lo tanto, en estrecha relación con el contexto social, político, sanitario y cultural/mediático no pueden ser vistos exclusivamente como mensajes y experiencias humorísticas. Aunque nos propongan otras maneras de relatar y procesar la tragedia de la pandemia, también expresan miradas, saberes, prácticas e incertidumbres... aunque indicarlo implique, como dice BALLESTEROS DONCEL (2016), "aguar" la fiesta.

\section{NOTAS}

1. Según el autor los hechos sociales totales movilizan, en ciertos casos, a la totalidad de la sociedad y de sus instituciones. Todos estos fenómenos son jurídicos, económicos, religiosos e, incluso, estéticos.

2. El objetivo del proyecto fue estudiar las medidas de Aislamiento Social Preventivo y Obligatorio (ASPO) y la infección por SARS-CoV-2 en la población con necesidades insatisfechas de vivienda y saneamiento del Área Metropolitana de la Gran Buenos Aires (AMBA) y el Área Metropolitana de Gran Resistencia en la provincia del Chaco (AMGR) en Argentina. Contó con financiamiento de la Agencia Nacional de Promoción de la Investigación, el Desarrollo Tecnológico y la Innovación del Ministerio de Ciencia y Tecnología de la Nación Argentina y es dirigido por la Dra. Andrea Mastrangelo, UNSAM/CONICET/ ANLIS-Malbrán.

3. Se refiere a la clásica distinción realizada por Eliseo Verón entre sociedad mediática (moderna) y sociedad mediatizada (posmoderna): una sociedad mediática se basa en una ideología representacional. Se considera que los medios representan (bien, mal) lo que sucede en la sociedad. Una sociedad mediatizada, en cambio, es aquella en la que las lógicas culturales empiezan a organizarse en función de las lógicas de los medios. Se considera que los medios ya no actúan bajo una lógica representacional, sino que son productores de sentido y constructores de acontecimientos (CARLÓN, 2020).

4. Por razones de extensión, seleccionamos los casos más representativos de cada categoría temática para ejemplificar lo analizado.

5. Tomamos el concepto de mandato de Lupton (1996) que se refiere al imperativo de la salud como un mandato cultural y moral en el que conservar y mejorar la salud se transformó en un valor estructurante de las sociedades contemporáneas expresando una medida del logro personal y de la vida correcta. 
6. Estrenada a principios de 2019 en Netflix, narra la historia de un adolescente socialmente incómodo, que es ambivalente sobre el sexo, debido a que su madre es una terapeuta sexual. A pesar de ello establece un negocio de consejería sexual para educar a sus compañeros sobre cómo lidiar con sus problemas sexuales.

7. La metáfora es una figura retórica por medio de la cual una realidad o concepto se expresan por medio de una realidad o concepto diferentes con lo que lo representado guarda cierta relación de semejanza/similitud.

8. Enunciada en el año 1996, el ex presidente afirmó durante un programa de televisión: "Dentro de poco tiempo se va a licitar un sistema de vuelos espaciales mediante el cual desde una plataforma, que quizá se instale en Córdoba, esas naves van a salir de la atmósfera, se van a remontar a la estratosfera, y desde ahí elegirán el lugar donde quieran ir, de tal forma que en una hora y media podremos estar en Japón, Corea o en cualquier parte del mundo y por supuesto, más adelante en otro planeta si se detecta vida" (Página 12, 14 de febrero de 2021). 9. En los primeros días de junio de 2020 y tras 80 días de prohibición, el gobierno de la Ciudad de Buenos Aires autorizó las salidas para correr, andar en bicicleta, en rollers o caminar. El mismo día en el que comenzó la habilitación, una marea de personas invadió los parques, plazas y bosques sin respetar el distanciamiento social.

10. Es uno de los superhéroes más populares y exitosos comercialmente. Creado en 1962 como personaje de comic, se transformó en un personaje insignia de Marvel, que ha aparecido en innumerables medios y soportes, incluidas series de televisión animadas y de acción en vivo, comics y películas. Spider-Verse es un evento de Marvel Comics protagonizado por Spider-Man donde se presen$\tan$ a todas sus versiones.

11. La metonimia es una figura retórica que consiste en designar una cosa con el nombre de otra con la que existe una relación de contigüidad espacial, temporal o lógica.

12. Estrenada en Australia en 1979, transcurre en un futuro apocalíptico marcado por la escasez de agua, petróleo y energía, crisis económica y el caos social. Mientras la sociedad se desintegra, una patrulla de policías se encarga de mantener la seguridad vial en algunas carreteras, dominadas por las pandillas. La película transcurre a partir de diferentes situaciones planteadas por el enfrentamiento entre el orden (la policía) y el caos (las pandillas) mostrando las contradicciones de cada uno de los bandos.

\section{REFERÊNCIAS}

AGUIAR, Raquel; SOARES DE ARAÚJO, Inesita. Fábula do viroceno: narrativas sobre heroísmo, solidariedade e novo normal. Revista Latinoamericana de Ciencias de la Comunicación, n. 35, p. 189-199, 2020.

ALONSO, Juan. El derecho a narrar. Disponible en: <www.hipermediaciones.com>. Acceso en: 20 jul. 2021.

ARDILA-GÓMEZ, Sara; ROSALES, Melina; FERNÁNDEZ, Marina; VELZI-DÍAZ, Alberto; MATKOVICH, Andrés; AGREST, Martín. Impacto de la pandemia por Covid-19 en los servicios de salud men- 
tal en Argentina. Rev. Argent. Salud Pública, n. 13 (Supl Covid-19), p. e26, 2021.

ARMUS, Diego. ¿Cómo se narra el coronavirus? Incertidumbres e historias globales. Revista N, 22 abr. 2020. Disponible en: <https:// www.clarin.com/revista-enie/ideas/-narra-coronavirus-incertidumbres-historias-globales_0_ot977nECw.html?fbclid=IwAR3-wKPconhy8L15VW9P-pleaWpZYQCHGxRKrOmVaqscrcGtLCV4sHj77Ys>. Acceso en: 20 jul. 2021.

ASSUSA, Gonzalo; KESSLER, Gabriel. Pandemia y crisis social: activación de repertorios históricos, exploraciones metodológicas e investigación sociológica. Prácticas de oficio, Investigación y reflexión en Ciencias Sociales. v.1, n. 25, p. 33-47, 2020.

BALLESTEROS DONCEL, Esmeralda. Circulación de memes en WhatsApp: ambivalencias del humor desde la perspectiva de género. EMPIRIA - Revista de Metodología de Ciencias Sociales, n. 35, p. 21-45, 2016. BENASSINI-FÉLIX, Claudia. Memes de Internet: multimodalidad, intertextualidad e interdiscursividad en tiempos de Covid-19. Virtualis. v.11, n. 21, p. 1-26, 2020.

CAMAROTTI, Ana; JONES, Daniel; GÜELMAN, Martín; DULBECCO, Paloma; CUNIAL, Santiago. Cambios en los patrones de consumo de bebidas alcohólicas en la cuarentena por Covid-19. Un estudio en el área metropolitana de Buenos Aires (Argentina). Revista de Salud Pública, Edición Especial, p. 37-50, 2020.

CANCELAS-OUVIÑA, Lucía. Humor in Times of Covid-19 in Spain: viewing coronavirus through memes disseminated via whatsapp. Front. Psychol, n. 12, p. 611788, 2021.

CARLÓN, Mario. Tras los pasos de Verón... Un acercamiento a las nuevas condiciones de circulación del sentido en la era contemporánea. Galáxia, n. 43, p. 5-25, 2020.

CARLÓN, Mario. La nueva visibilidad de los gestos: sobre los mordiscos de Mike Tyson. deSignis, n. 3, p. 159-172, 2002.

COSTA DAMASCENO, Handherson. Memes e narrativas em tempos de pandemia da Covid-19: um estudo analítico. Folha de rosto - Revista de Biblioteconomia e Ciência da Informação, v. 6, n. 2, p. 119$135,2020$.

DEMONTE, Flavia. ¿Comer como el discurso médico-nutricional manda? Discursos y prácticas sobre alimentación saludable en sectores medios de la ciudad de Buenos Aires, Argentina. Población y Salud en Mesoamérica, v. 18, n. 2, 2021.

DÍAZ LANGOU, Gala; KESSLER, Gabriel; DELLA PAOLERA; Carola; KARCZMARCZYK, Matilde. Impacto social del Covid-19 en Argentina. Balance del primer semestre de 2020. Buenos Aires: CIPPEC, 2020.

ESCUDERO CHAUVEL, Lucrecia. Antropología Cultural del Meme Covid-19: estrategias de comunicación entre epidemia y pandemia. Revista Chilena de Semiótica, n. 14, p. 6-24, 2020. 
ETCHEVERS, Martín; GARAY, Cristian; PUTRINO, Natalia; GRASSO, Jimena; NATALÍ, Vanesa; HELMICH, Natalia. Salud Mental en Cuarentena. Relevamiento del impacto psicológico a los 7-11, 50-55 y 115- 124 días de cuarentena en población argentina. Buenos Aires: Observatorio de Psicología Social Aplicada - UBA, 2020.

FRATICELLI, Damián; ANTIVERO, Javier. Sociedad hipermediatizada. Revista Sociedad, n. 39, p. 1-4.

FRATICELLI, Damián. La pandemia del humor. 2020. Disponible en: $<$ www.hipermediaciones.com>. Acceso en: 20 jul. 2021.

INADI - INSTITUTO NACIONAL CONTRA LA DISCRIMINACIÓN, LA XENOFOBIA Y EL RACISMO. Discursos discriminatorios y gordofobia. Buenos Aires: INADI, 2020.

JOHNSON, María; SALETTI-CUESTA, Lorena; TUMAS, Natalia. Emociones, preocupaciones y reflexiones frente a la pandemia del Covid-19 en Argentina. Ciência \& Saúde Coletiva, v. 25, p. 24472456, 2020.

KESSLER, Gabriel; BENZA, Gabriela. ¿Impactará la crisis de covid-19 en la agenda social de América Latina? Nueva Sociedad. Disponible en: <htttp://nuso.org/articulo/impactara-la-crisis-de-covid-19-enla-agenda-social-de-america-latina $>$. Acceso en: 20 jul. 2021.

KESSLER, Gabriel; DIVIRGILIO, Mercedes. La nueva pobreza urbana: dinámica global, regional y argentina en las últimas dos décadas. $R e-$ vista de la CEPAL, n. 95, p. 31-50, 2008.

LENGUITA, Paula. Luchas feministas, cuidados y comunidad en la post-pandemia. Telos: revista de Estudios Interdisciplinarios en Ciencias Sociales, v.1, n. 23, p. 141-149, 2021.

LUPTON, Deborah. Food, the body and the self. Londres: Sage Publications, 1996.

MAUSS, Marcel. Sociología y antropología. Madrid: Tecnos, 1991.

MASTRANGELO, Andrea. Perspectivas socio antropológicas para el estudio local de la pandemia Covid-19 en Argentina. Ponto Urbe, n. 27, p. 1-18, 2020.

MARCÚS, Juliana; BOY, Martín; BENITEZ, Joaquín; BERARDO, Martina; MÁRQUEZ, Agustina; PERALTA, María; VÁZQUEZ, Diego. Cambios en los usos y valoraciones de los espacios públicos y privados en la Región Metropolitana de Buenos Aires: la vida cotidiana en tiempos de aislamiento obligatorio por Covid-19. Buenos Aires: Instituto de Investigaciones Gino Germani, 2020.

MENÉNDEZ, Eduardo. Consecuencias, visibilizaciones y negaciones de una pandemia: los procesos de autoatención. Salud Colectiva, v. 16, p. e3149, 2000.

REIS INSFRAN, Milena; SADDI CHAVES, Aline. Humor e crítica nos memes da pandemia de covid-19: uma análise dialógica. Philologus, v. 26, n. 78 , p. 1780-1796, 2020. 
RIVAS CARMONA, María; CALERO VAQUERO, María. Pandemia y posverdad: el impacto de la Covid-19 en la comunicación por whatsapp. Revista Prisma Social, n. 31, p. 110-154, 2020.

RODRÍGUEZ CEBERIO, Marcelo; JONES, Gilda; BENEDICTO, María. Covid-19: Ansiedad de rasgo y estado en una población seleccionada de Argentina en un contexto de cuarentena extendida. Rev Argent Salud Pública, n. 13, p. e22, 2021.

RUIZ MARTÍNEZ, José. Una aproximación retórica a los memes de Internet. Revista Signa, n. 27, p. 995-1021, 2018.

SAEZ, Virginia; CARP, Dafne. Memes sobre las tecnologías en las escuelas: un estudio de las producciones estudiantiles. Cuadernos.info, n. 49, p. 281-301, 2021.

SALGADO ANDRADE, Eva. Memes y procesos de semiosis de la pandemia en México. Comunicación y Sociedad, n. 18, p. 1-22, 2021.

SAINT LAURENT, Constance; GLĂVEANU, Vlad; LITERAT, Ioana. Internet memes as partial stories: identifying political narratives in coronavirus memes. Social Media + Society, p. 1-13, 2021.

SCOLARI, Carlos. En busca del relato perdido. Disponible en: <http:// www.hipermediaciones.com>. Acceso en: 20 jul. 2021.

SOLA-MORALES, Salomé. Humor en tiempos de pandemia. Análisis de memes digitales sobre la Covid-19. Zer, v. 25, n. 49, p. 33-58, 2020.

SUDRIÁ, María; ANDREATTA, María; DEFAGÓ, María. Los efectos de la cuarentena por coronavirus (Covid-19) en los hábitos alimentarios en Argentina. DIAETA, v. 38, n. 171, p. 10-19, 2020.

ZIBECHI, Raúl. A las puertas de un nuevo orden mundial. En: Sopa de Wuhan. Buenos Aires: ASPO, 2020.

ZIZEK, Slavoj. El coronavirus es un golpe al capitalismo a lo Kill Bill... En: Sopa de Wuhan. Buenos Aires: ASPO, 2020.

SUBMETIDO EM: 23/07/2021

APROVADO EM: 10/11/2021 